\title{
Clinical Utility of Triglyceride: HDL-Cholesterol Ratio as a Surrogate Marker of Inflammation in Pediatric Obesity
}

\author{
Kawadry $\mathrm{O}^{1}$, Kichler $\mathrm{J}^{2}$, Hoffmann $\mathrm{RG}^{3}$, Dasgupta $\mathrm{M}^{3}$ and Alemzadeh $\mathrm{R}^{* 4}$ \\ ${ }^{1}$ Department of Pediatrics, Advocate Christ Medical Center, Chicago, IL, USA \\ ${ }^{2}$ Cincinnati Children's Hospital, Cincinnati, OH, USA \\ ${ }^{3}$ Medical College of Wisconsin, Milwaukee, WI, USA \\ ${ }^{4}$ University of Tennessee Health Science Center \& Le Bonheur Children's Hospital, Memphis, TN, USA
}

${ }^{*}$ Corresponding author: Alemzadeh R, MD., Professor of Pediatrics, Section of Pediatric Endocrinology, University of Tennessee Health Science Center, Le Bonheur Children's Hospital FOB, Rm 116, 49 N. Dunlap Street, Memphis, TN, USA 38105, Fax: (901) 287-7450, Tel: (901)287-7425, E-mail: ralemzad@uthsc.edu

Citation: Kawadry O, Kichler J, Hoffmann RG, Dasgupta M, Alemzadeh R (2016) Clinical Utility of Triglyceride: HDL-Cholesterol Ratio as a Surrogate Marker of Inflammation in Pediatric Obesity. J Obes Overweig 2(3): 302. doi: 10.15744/2455-7633.2.302

Received Date: September 21, 2016 Accepted Date: November 28, 2016 Published Date: November 30, 2016

\begin{abstract}
Objective: The prognostic utility of the triglyceride: HDL-cholesterol (TG:HDL-C) ratio, a marker for insulin resistance, is unknown among high-risk children and adolescents. We examined the clinical utility of TG:HDL-C ratio as a marker of insulin resistance and chronic inflammation in obese youth.

Materials and Methods: Body mass index (BMI), body composition, fasting lipids, glucose, high sensitivity c-reactive protein (hs-CRP), $\mathrm{HbA}_{1 \mathrm{c}}$, insulin and the homeostatic model assessment for insulin resistance (HOMA-IR) were evaluated in 133 obese pubertal subjects $(86 \mathrm{~F} / 47 \mathrm{M})$, aged $13.9 \pm 2.3$ years [55 Caucasian $(\mathrm{C}), 40$ Hispanic $(\mathrm{H}), 38$ African American (AA)] [body mass index z-score (BMI-z) 2.4 $\pm 0.3]$.

Results: The $\mathrm{C}$ and $\mathrm{H}$ subgroups had higher TG, TG: HDL-C and hs-CRP values and prevalence of metabolic syndrome (MS) compared to AA subgroup $(58.2 \%$ and $62.5 \%$ vs. $44.5 \%$, $\mathrm{p}<0.05)$ without gender differences. There was a positive correlation between hs-CRP and fat mass (FM) within each gender. The TG: HDL-C ratio correlated with HOMA-IR $(r=0.20, p<0.05)$, and hs- CRP $(r=0.46, p<0.0001)$ when controlling for FM, gender and ethnicity. Further, TG: HDL-C ratio of 3.0 provided a sensitivity of $89.2 \%$ and specificity of $84.8 \%$ $(\mathrm{p}<0.0001)$ for detection of MS. However, a HOMA-IR cut-off value for TG: HDL-C ratio could not be calculated. On the other hand, an hs-CRP cut-off point of $2.0 \mathrm{mg} / \mathrm{L}$ provided a sensitivity of $58 \%$ and specificity of $80 \%$ for a TG: HDL-C ratio of 3.0.

Conclusion: The TG: HDL-C ratio correlated with markers of insulin resistance and inflammation. Nevertheless, the TG: HDL-C ratio may be a more reliable independent marker for inflammation than HOMA-IR for the identification of atherosclerosis risk in obese children and adolescents.
\end{abstract}

Keywords: Obesity; Insulin Resistance; Inflammation; Diabetes; Dyslipidemia

List of Abbrevations: AA: African American; BMI-z: Body Mass Index z-score; C: Caucasian; CMR: Cardiometabolic Risk; FM: Fat Mass; $\mathrm{HbA}_{1 \mathrm{c}}$ : Hemoglobin $\mathrm{A}_{1 \mathrm{c}}$; hs-CRP: Highly Sensitive C-Reactive Protein; H: Hispanic; HOMA- IR: Homeostatic Model Assessment for Insulin Resistance; MS: Metabolic Syndrome; ROC: Receiver-Operating Characteristic; TG:HDL-C: Triglyceride: HDL- Cholesterol Ratio

\section{Introduction}

Cardiovascular disease is the most common cause of death among the adult population, and it has been documented that risk factors associated with its development may appear as early as childhood [1]. Cardiometabolic risk (CMR) factors tend to precede the development of atherosclerosis in obese children and adults [2]. Indeed, diagnostic correlates of pediatric metabolic syndrome (MS) have been shown to predict adult MS, heart disease mortality and type 2 diabetes mellitus (T2DM) [2-4]. Further, implementation of increased physical activity in pediatric obesity prevention trials has demonstrated improvements in markers of insulin resistance and inflammation [5]. Therefore, clinically reliable and cost-effective tools to identify and predict CMR factors in children and adolescents are critical for prevention of MS.

The triglyceride: HDL-cholesterol (TG: HDL-C) ratio has been proposed as a simple tool to identify subjects with insulin resistance and MS, and can predict coronary artery disease [6,7]. Potential mechanisms that may explain the relationship between insulin sensitivity and TG: HDL-C ratio could be free fatty acid concentrations, adipose tissue adipokines such as leptin and adiponectin 
levels, physical activity energy expenditure, gene expression and diet [8]. Indeed, it has been shown that obese youth with insulin resistance and dyslipidemia have impaired suppression of lipid oxidation and elevated free fatty acid concentrations in response to insulin infusion [9].

High-sensitivity c-reactive protein (hs-CRP) has emerged as a useful biomarker for vascular inflammation associated with atherosclerosis [10]. Increased circulating hs-CRP levels predict acute coronary events not only in patients with cardiovascular disease, but also in apparently healthy subjects [11]. Many studies in adults have shown that hs-CRP levels are associated with adverse lipid profiles, such as increases in TG levels and decreases in HDL-C levels [12,13]. There are few studies exploring the relationship between hs-CRP and certain risk of cardiovascular disease among children [14].

Data from the Third National Health and Nutritional Examination Survey (NHANES III) indicate that the most frequently encountered components of the MS among adolescents are high circulating TG) (25-30\% of adolescents) and low HDL-cholesterol (HDL-C) levels (40-50\% of adolescents) [15]. Using hyperinsulinemic-euglycemic clamp, Hannon et al. showed that a cutoff point of TG: HDL-C $\geq 3.0$ had a sensitivity of $61 \%$ and a specificity of $82 \%$ for identifying overweight pediatric cohort in the lowest tertile for insulin sensitivity [16]. To date, the clinical utility of TG: HDL-C ratio in identifying CMR factors in pediatric obesity has not been studied. Therefore, we evaluated the relationship between TG: HDL-C ratio and indices of insulin resistance and low grade inflammation in a group of obese children and adolescents.

\section{Materials and Methods}

\section{Subjects and Design}

One hundred thirty-three pubertal children (8.8-18.4 years; Tanner stage 2-5) who met the criteria for obesity (BMI $>95^{\text {th }}$ percentile for age) [17] were included in the study. All subjects were evaluated at the Children's Hospital of Wisconsin (CHW) (affiliated with the Medical College of Wisconsin) Endocrine Clinic for obesity between January 2003 and October 2008. Race/ ethnicity was self-assigned: Caucasian ( $\mathrm{C} ; \mathrm{n}=55,41.4 \%)$, Mexican American (Hispanic $\mathrm{H} ; \mathrm{n}=40,30.1 \%$ ), and African American $(\mathrm{AA} ; \mathrm{n}=38,28.6 \%)$. Children with cardiac, endocrine, renal, infectious, and chronic conditions and medical therapies that could affect cardiovascular or metabolic function were excluded from the study. The CHW Institutional Review Board approved the retrospective review of patients' clinical charts; therefore, informed consent was not required.

Data was collected on patients including age, sex, self-declared ethnicity, height, weight, and body composition analysis that was performed by bioelectrical impedance (BIA) (TANITA- TBF-410; TANITA America, Arlington Heights, IL) [18]. Each patient's height was measured using a Harpenden stadiometer. Subjects and/or their guardians completed a questionnaire detailing their medical history and medications. Two measurements of right arm systolic and diastolic blood pressure (SBP and DBP) were performed 2 times 10 minutes apart and the mean values of the two measurements were recorded. Pubertal development was assessed by Tanner stage of breast development in girls and testicular volume in boys by two pediatricians. Fasting serum samples were obtained for the determination of glucose, insulin, lipid profile, hs-CRP, and $\mathrm{HbA}_{1 c}$.

\section{Laboratory studies and calculations}

Serum glucose was measured by an autoanalyzer (Orthodiagnostics Fusion 5.1; Orthodiagnostics, Rochester, NY). The hs-CRP assays were carried out using a polystyrene particle-enhanced immunonephelometric method (Dade Behring BNII). The detection limit of this assay was $0.20 \mathrm{mg} / \mathrm{L}$ with measuring range of 0.18 to $1150 \mathrm{mg} / \mathrm{L}$ with intraassay and interassay coefficients of variance of 2.65 and 3.6\%, respectively (Quest Diagnostics, San Jose, CA). Hs-CRP levels $>10 \mathrm{mg} / \mathrm{L}$ were eliminated from the study, to avoid the influence of acute infection.

Fasting serum insulin was measured by Nichols radio-immunoassay (RIA) (Nichols Institute, San Clemente, CA) with intraassay and inter-assay coefficients of variation (CV) of 2.4-6.3\% and 5.2-13.0\%, respectively. The homeostatic model assessment estimates for insulin resistance (HOMA-IR) calculated as previously described [19]: HOMA-IR= (blood glucose $\mathrm{mmol} / \mathrm{L} \mathrm{x}$ insulin $\mu \mathrm{U} / \mathrm{mL}) / 22.5)$.

Total cholesterol, high-density lipoprotein Cholesterol (HDL-C) and triglycerides (TG) were determined by colorimetric methods (Beckman spectrophotometer, Fullerton, CA). Low- density lipoprotein cholesterol (LDL-C) was calculated using Friedewald's equation [20]. A cut- off point of TG $(\mathrm{mg} / \mathrm{dL})$ : HDL-C $(\mathrm{mg} / \mathrm{dL})$ ratio $\geq 3.0$ was used to define insulin resistance [16].

Since waist circumference was not obtained in this cohort, the international diabetes federation (IDF) criteria for diagnosis of MS was not used [21]. Therefore, modified National Cholesterol Education Program (NCEP) criteria [22] for diagnosis of MS were defined as the presence of 3 or more of the following: age-adjusted BMI $>95^{\text {th }}$ percentile, systolic or diastolic $\mathrm{BP}>90^{\text {th }}$ percentile, TG $>90^{\text {th }}$ percentile, HDL cholesterol $<5^{\text {th }}$ percentile, and impaired fasting glucose $>5.6 \mathrm{mmol} / \mathrm{L}$.

\section{Statistical analysis}

Statistical analyses were carried out using SPSS (version 14.0; SPSS, Chicago, IL). Data are expressed as mean \pm SD unless otherwise 
specified. Spearman rank correlation was used to study the relationship between variables; partial correlations were used to control for potential covariates (eg, FM, gender, Tanner stage and ethnicity). ANOVA was used for normally distributed variables. Chisquare analysis was used to compare prevalence of MS. The Kruskal- Wallis Test was used for variables with skewed distributions for the overall comparisons. Fisher Z transformation was used to compare two correlations. Student's t-test and Mann-Whitney non-parametric test were used to compare means and mean ranks, respectively. $\mathrm{P}<0.05$ was considered statistically significant.

Receiver-operating characteristic (ROC) curves were constructed using logistic regression to identify cut-off points for the TG: HDL-C ratio, which optimized the sensitivity and specificity of these biomarkers to identify youth with inflammation. The ROC curves were constructed by plotting the true-positive rate (sensitivity) against the false-positive rate (1- specificity) over a range of cut-off values. The cut-off points used in this analysis were determined by choosing the coordinates of the curve that provided the highest sensitivity, without compromising specificity.

\section{Results}

Table 1 summarizes the clinical and biochemical characteristics of the entire participant cohort stratified according to ethnicity. Table 2 applies the Kruskal-Wallis test for ethnicity. Overall comparison results across the ethnic groups were reported. There were no differences in FM, BMI-z, serum glucose, HOMA-IR, cholesterol, LDL-C, HDL-C. The serum TG levels, TG: HDL-C ratios and hs-CRP values were significantly higher in $\mathrm{H}$ and $\mathrm{C}$ than $\mathrm{AA}(\mathrm{p}<0.05, \mathrm{p}<0.01$, respectively). This corresponded to higher prevalence of $\mathrm{MS}$ among $\mathrm{C}$ and $\mathrm{H}$ subgroups compared to AA subgroup (58.2\% and $62.5 \%$ vs. $44.5 \%, \mathrm{p}<0.05)$ : [(AA vs. H: $x^{2}=6.52$, $\mathrm{p}=-.0015, \mathrm{RR}=1.45,95 \% \mathrm{CI}: 1.08-1.95)$, (AA vs. $\left.\mathrm{C}: x^{2}=3.90, \mathrm{p}=0.047, \mathrm{RR}=1.33,95 \% \mathrm{CI}=1.01-1.77\right)$ and $\left(\mathrm{C}\right.$ vs. $\mathrm{H}: x^{2}=0.32, \mathrm{p}=0.56$, $\mathrm{RR}=0.92,95 \% \mathrm{CI}=0.69-1.2)]$. Conversely, $\mathrm{HbA}_{1 \mathrm{c}}$ was significantly higher in AA and $\mathrm{H}$ than $\mathrm{C}(\mathrm{p}<0.05)$. However, there were no gender differences in TG: HDL-C ratio, hs-CRP, and $\mathrm{HbA}_{1 \mathrm{c}}$ levels. While hs-CRP was positively correlated with FM without gender differences $(\mathrm{r}=0.40 ; \mathrm{p}<0.01)$, the correlation between TG: HDL-C and FM was not significant.

\begin{tabular}{|c|c|c|c|c|}
\hline Parameter & All & Caucasians $(\mathrm{C})$ & Hispanics (H) & African Americans (AA) \\
\hline $\mathrm{N}(\%)$ & 133 & $55(41.4)$ & $40(30.1)$ & $38(28.6)$ \\
\hline Age (years) & $13.9 \pm 2.3$ & $14.2 \pm 2.0$ & $13.4 \pm 2.1$ & $14.0 \pm 2.6$ \\
\hline Gender ( $\%$ female) & 64.7 & 63.6 & 62.5 & 68.4 \\
\hline Tanner Stage & $3.8 \pm 1.0$ & $3.9 \pm 1.0$ & $3.7 \pm 1.0$ & $3.9 \pm 1.1$ \\
\hline BMI-z & $2.4 \pm 0.3$ & $2.4 \pm 0.4$ & $2.4 \pm 0.3$ & $2.5 \pm 0.3$ \\
\hline Fat Mass (\%) & $44.9 \pm 7.7$ & $44.1 \pm 8.3$ & $45.1 \pm 6.2$ & $45.9 \pm 8.2$ \\
\hline Systolic blood pressure (mm Hg) & $127 \pm 14$ & $129 \pm 15$ & $125 \pm 10$ & $127 \pm 17$ \\
\hline Diastolic blood pressure (mm Hg) & $68 \pm 9$ & $69 \pm 9$ & $66 \pm 7$ & $69 \pm 10$ \\
\hline Glucose $(\mathrm{mmol} / \mathrm{L})$ & $5.0 \pm 0.4$ & $5.0 \pm 0.4$ & $5.0 \pm 0.4$ & $4.9 \pm 0.4$ \\
\hline Insulin (pmol/L) & $211.0 \pm 112.0$ & $197.1 \pm 98.6$ & $205.6 \pm 95.6$ & $236.7 \pm 141.3$ \\
\hline HOMA-IR & $6.6 \pm 3.6$ & $6.1 \pm 3.1$ & $6.6 \pm 3.2$ & $7.4 \pm 4.4$ \\
\hline $\mathrm{HbA}_{1 \mathrm{c}}(\%)$ & $5.3 \pm 0.4$ & $5.1 \pm 0.4$ & $5.3 \pm 0.4$ & $5.4 \pm 0.4^{\mathrm{a}}$ \\
\hline Cholesterol (mmol/L) & $4.8 \pm 0.9$ & $4.7 \pm 0.8$ & $4.7 \pm 0.9$ & $4.8 \pm 0.9$ \\
\hline $\mathrm{LDL}-\mathrm{C}(\mathrm{mmol} / \mathrm{L})$ & $2.9 \pm 0.7$ & $2.8 \pm 0.6$ & $2.7 \pm 0.8$ & $3.1 \pm 0.8$ \\
\hline $\mathrm{HDL}-\mathrm{C}(\mathrm{mmol} / \mathrm{L})$ & $1.06 \pm 0.3$ & $1.07 \pm 0.3$ & $1.01 \pm 0.3$ & $1.10 \pm 0.3$ \\
\hline $\mathrm{TG}(\mathrm{mmol} / \mathrm{L})$ & $1.72 \pm 0.7$ & $1.81 \pm 0.7$ & $1.82 \pm 0.8$ & $1.45 \pm 0.8^{\mathrm{a}}$ \\
\hline TG:HDL-C & $4.1 \pm 2.5$ & $4.2 \pm 2.3$ & $4.4 \pm 2.2$ & $3.5 \pm 2.9^{a}$ \\
\hline hs-CRP (mg/L) & $3.1 \pm 1.2$ & $3.3 \pm 1.1$ & $3.2 \pm 1.0$ & $2.5 \pm 1.3^{b}$ \\
\hline Metabolic Syndrome (\%) & 55.6 & 58.2 & 62.5 & $44.7^{\mathrm{a}}$ \\
\hline \multicolumn{5}{|c|}{$\begin{array}{l}\text { Data are expressed as mean } \pm \mathrm{SD} \\
{ }^{\mathrm{a}} \mathrm{p}<0.05 ; \mathrm{AA} \text { vs. } \mathrm{C} \text { and } \mathrm{H} \\
{ }^{\mathrm{b}} \mathrm{p}<0.01 \text {; AA vs. } \mathrm{C} \text { and } \mathrm{H}\end{array}$} \\
\hline
\end{tabular}

\begin{tabular}{|c|c|c|c|c|}
\hline & Caucasian $(\mathbf{C})$ & Hispanic $(\mathbf{H})$ & African American $(\mathbf{A A})$ & KW p-value \\
\hline $\mathrm{N}$ & 55 & 40 & 38 & NA \\
\hline TG: HDL Ratio & $4.2 \pm 2.3$ & $4.4 \pm 2.2$ & $3.5 \pm 2.9^{\mathrm{a}, \mathrm{b}}$ & 0.02 \\
\hline $\mathrm{hsCRP}(\mathrm{mg} / \mathrm{L})$ & $3.3 \pm 1.1$ & $3.2 \pm 1.0$ & $2.5 \pm 1.3^{\mathrm{b}}$ & 0.006 \\
\hline $\mathrm{HbA}_{\mathrm{lc}}(\%)$ & $5.1 \pm 0.4$ & $5.3 \pm 0.4$ & $5.4 \pm 0.4^{\mathrm{c}}$ & 0.0006 \\
\hline
\end{tabular}

Data are expressed as mean \pm SD; Mann-Whitney Wilcoxon Test has been used for each pair ${ }^{\mathrm{a}} \mathrm{p}<0.05$, AA vs. C ${ }^{\mathrm{b}} \mathrm{p}<0.01$ AA vs. $\mathrm{H}$ c $<<0.001$ AA vs. C

Table 2: Kruskal-Wallis (KW) test for Ethnicity 
Table 3 summarizes the bivariate correlations while controlling for FM, gender, and ethnicity using Spearman rank partial correlations. The TG: HDL-C ratio was correlated with HOMA-IR $(r=0.20, \mathrm{p}<0.05)$ and hs-CRP $(\mathrm{r}=0.46, \mathrm{p}<0.0001)$. While HOMA-IR was correlated with $\mathrm{HbA}_{1 \mathrm{c}}(\mathrm{r}=0.24, \mathrm{p}<0.01)$, there was no correlation between HOMA-IR and hs-CRP, or between hs-CRP and $\mathrm{HbA}_{1 \mathrm{c}}$.

\begin{tabular}{l|c|c|c|c|}
\hline Variable & TG:HDL-C & HOMA-IR & hs-CRP & HbA $_{\text {lc }}$ \\
\hline TG:HDL-C & 1.00 & $0.20^{\mathrm{a}}$ & $0.46^{\mathrm{c}}$ & 0.01 \\
\hline HOMA-IR & & 1.00 & 0.14 & $0.24^{\mathrm{b}}$ \\
\hline hs-CRP & & & 1.00 & -0.04 \\
\hline HbA $_{\text {lc }}$ & & & & 1.00 \\
\hline
\end{tabular} $\begin{aligned} & { }^{\mathrm{a}} \mathrm{p}<0.05 \\
& { }^{\mathrm{b}} \mathrm{p}<0.01 \\
& { }^{\mathrm{c}} \mathrm{p}<0.001 \\
& \text { Table 3: Bivariate correlations controlling for FM, gender, and ethnicit }\end{aligned}$

\section{TG:HDL-C Receiver-operating characteristic curves for different hs-CRP cutoffs}

Figure 1 and Table 4 show the TG: HDL-C ratio ROC curves at different hs-CRP cut-off points. An hs-CRP cutoff $=2.0$ gives the highest predictability (highest sensitivity and specificity combination) for TG: HDL-C ratio. An hs-CRP cut-off point of 2.0 gives a sensitivity of $58 \%$ and a specificity of $80 \%$ for a TG: HDL-C ratio of 3.0. A HOMA-IR cut-off point for TG: HDL- C ratio with an acceptable sensitivity and specificity could not be determined. Finally, TG: HDL-C ratio of 3.0 provided a sensitivity of $89.2 \%$ and specificity of $84.8 \%$ for detection of MS (AUC $=0.94$, standard error $=0.0196,95 \% \mathrm{CI}=0.8995-0.994, \mathrm{p}<0.0001)$.

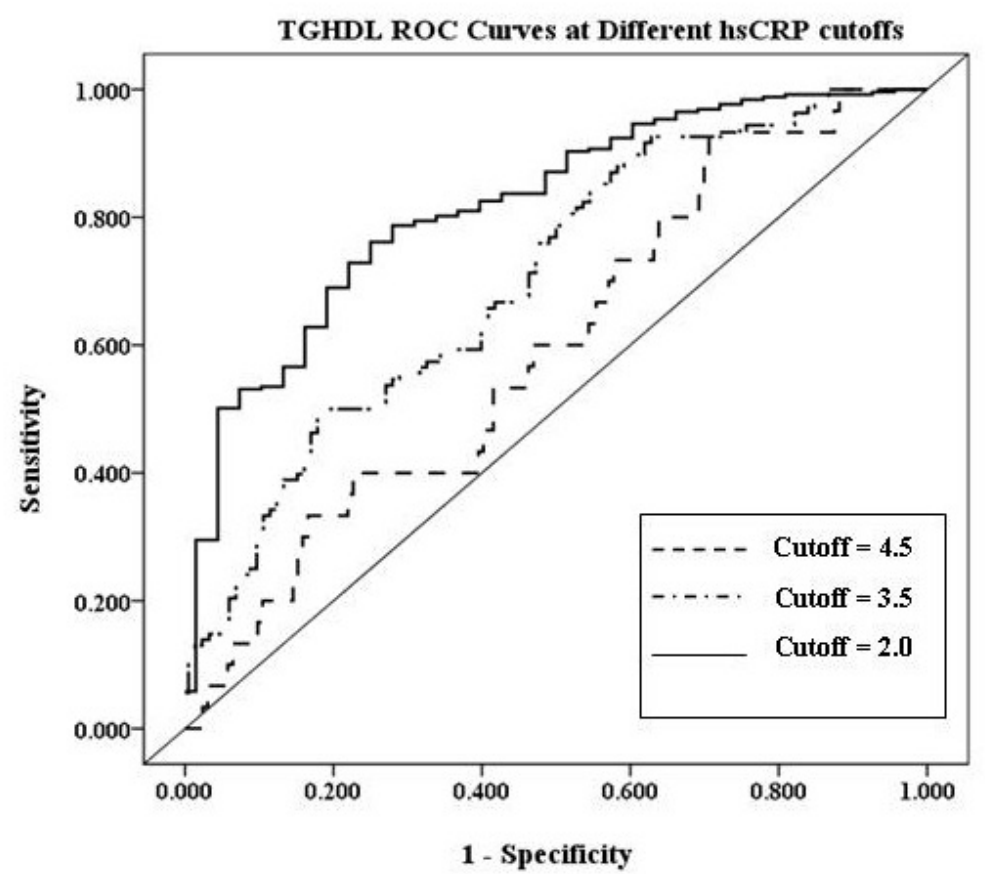

Figure 1: TG:HDL-C ratio ROC curves at different hs-CRP cutoffs

\begin{tabular}{|c|c|c|}
\hline $\begin{array}{c}\text { hs-CRP } \\
\text { Cut-off }\end{array}$ & Sensitivity & Specificity \\
\hline 2.0 & $58 \%$ & $80 \%$ \\
\hline 3.0 & $59 \%$ & $80 \%$ \\
\hline 3.5 & $51 \%$ & $78 \%$ \\
\hline 4.0 & $54 \%$ & $60 \%$ \\
\hline 4.5 & $50 \%$ & $54 \%$ \\
\hline
\end{tabular}

Table 4: TG: HDL-C ratio ROC curves at different cut-offs for hs-CRP

\section{Discussion}

In this study, we observed that measures of inflammation (hs-CRP) and dyslipedemia (TG: HDL-C ratio) were significantly higher in $\mathrm{H}$ and $\mathrm{C}$ than $\mathrm{AA}$ without gender differences. The prevalence of MS was higher among $\mathrm{H}$ and $\mathrm{C}$ subgroups compared to AA 
subgroup. Conversely, $\mathrm{HbA}_{1 \mathrm{c}}$ was significantly higher in AA than $\mathrm{H}$ and $\mathrm{C}$. Also, there was a correlation between FM and hs-CRP within each gender without gender differences. Furthermore, TG: HDL-C ratio correlated with both indices of insulin resistance and inflammation even after controlling for confounding factors. An hs-CRP cut-off point of 2.0 was found to give a sensitivity of $58 \%$ and a specificity of $80 \%$ for a TG: HDL-C ratio of 3.0 .

Previously, Hannon et al. showed that a cutoff point of TG: HDL-C $\geq 3.0$ had a sensitivity of $61 \%$ and a specificity of $82 \%$ for identifying overweight individuals in the lowest tertile for insulin sensitivity, despite having percent body fat comparable to those subjects with values below the cut-off point [16]. However, the study was not powered to determine the sensitivity, specificity, and predictive values of lipid markers for clinical prediction of insulin resistance. Also, Dhuper et al. found that HOMA-IR had a correlation with TG: HDL-C ratio, but, the correlation was not controlled for FM [23]. In contrast, Quijada et al. observed that the TG: HDL-C ratio correlated with all markers of obesity and mean blood pressure, but not HOMA-IR [24] suggesting that the expression of insulin resistance in obese pediatric subjects is heterogeneous. However, we observed that TG: HDL-C cutoff of 3.0 was a marker for detecting MS.

Sumner et al. reported that the TG: HDL-C ratio is not a reliable marker of insulin resistance in AA adults [25] since AA subjects tend to display higher lipoprotein lipase (LPL) activity with resultant lower TG levels in this ethnic group compared to C cohort [26]. Hence, insulin resistance leads to an impairment of LPL levels and high TG levels in C, but not in AA subjects [27]. While the TG: HDL-C ratio $\geq 3.0$ failed to predict insulin resistance in all three ethnic groups, it predicted MS in our cohort. Our observations differ from those of Sumner et al. which may be attributed to genetic variants and age-related changes in the effects of LPL within individuals over time [28].

It has been shown that hs-CRP is a major player in the atherosclerotic process at all stages [28,30]. The evaluation of CMR factors in Young Finns Study showed that the correlation between hs-CRP and carotid intima-media thickness is driven by the effects of adiposity [31]. This interaction between hs-CRP, TG and HDL-C could be mediated by different cytokines of adipose origin, such as tumor necrosis factor-alpha (TNF- $\alpha$ ) and interleukin-6 (IL-6). The hs- CRP levels are elevated in some genetically predisposed individuals in relation to greater abdominal adiposity [32]. In our study, hs-CRP correlated with TG: HDL-C ratio while controlling for FM. While the association with most CMR factors appears to be due to the confounding effects of adiposity [33], our finding is unique in that it shows the presence of low grade inflammation during childhood prior to the development of atherosclerosis and cardiovascular disease [34].

In adults, an hs-CRP value $>1.0$ has been shown to be an independent predictor for future cardiovascular events [34]. In children, however, there is a lack of evidence for defining critical cut-off points for hs-CRP. Guren et al. found that an hs-CRP > 1.04 mg/L had $58 \%$ sensitivity and $92 \%$ specificity of identifying children with coronary heart disease risk factors [35]. However, the relationship between hs-CRP and CMR factors was not adjusted for FM especially since the increased levels of hs-CRP were likely the consequence of underlying adiposity rather than the atherosclerotic process. In our study, we observed that a hs-CRP cut-off point of 2.0 gave a sensitivity of $58 \%$ and a specificity of $80 \%$ for a TG: HDL-C ratio of 3.0. Recently, Di Bonito et al. reported that TG: HDL-C ratio $\geq 2.0$ was associated with several CMR factors and preclinical signs of cardiac abnormalities in a group of Caucasian children and adolescents [36]. However, they did not examine the relationship between TG: HD-C ratio and hs-CRP. Therefore, prospective studies with larger multi-ethnic population are needed to investigate the progression of hs-CRP values, their association with cardiovascular events, and the influence of hs-CRP lowering therapy.

There are well-documented differences in hs-CRP concentration distribution among different ethnic groups. The NHANES 19992000 showed that hs-CRP levels were higher in $\mathrm{H}$ than in $\mathrm{C}$ and AA groups after adjusting for age, BMI percentiles, smoking status, systolic blood pressure, and total cholesterol concentration [37]. In our study, $\mathrm{C}$ and $\mathrm{H}$ groups displayed higher hs-CRP levels than AA group. Hs-CRP levels were also higher in $\mathrm{C}$ than in $\mathrm{H}$ subjects, but this did not reach statistical significance.

Numerous studies have linked measures of adiposity to measures of inflammation in children without gender differences. Syme et al. showed that excess intra-abdominal fat was associated with higher hs-CRP levels in both female and male adolescents [38]. Similarly, the correlation between hs-CRP and FM was not significantly different across gender in our cohort. Contrary to our findings, Khera et al. showed that the quantity and distribution of body fat and sex-related differences in the inflammatory response to adiposity may influence hs-CRP levels to a greater extent in women as compared to men [39]. They used dual-energy x-ray absorptiometry and abdominal magnetic resonance imaging to quantify regional adipose tissue distribution. Finally, our cohort included children and adolescents in varying stages of puberty which may account for lack of gender differences in hs-CRP.

Also, there are also well-documented ethnic differences in $\mathrm{HbA}_{1 \mathrm{c}}$ concentration distribution among diabetic and healthy children. Similar to data from the Third NHANES [40], we observed higher $\mathrm{HbA}_{1 \mathrm{c}}$ levels in AA than C. Our study also showed that HbA ${ }_{1 c}$ was higher in AA than $\mathrm{H}$. Both findings suggest that physiologic or genetic factors may contribute to racial differences in $\mathrm{HbA}_{1 \mathrm{c}} \mathrm{glycation}$ [41] independent of glucose concentration, but its impact on long- term complications is unknown.

Limitations to this study include lack of oral glucose tolerance data to assess glucose homeostasis and $\beta$-cell function in relationship to the TG: HDL-C ratio, particularly since HbA1c values were higher in AA group compared to $\mathrm{C}$ and $\mathrm{H}$ groups. The possible presence of impaired glucose tolerance among some of the participant cohort may have influenced our results [42]. Another limitation to the 
study is that there was no age- and sex-matched normal-weight controls for each ethnic group, and controls having children with impaired glucose tolerance and T2DM. Finally, a prospective study will be needed to further address the hypothesis that markers of dyslipidemia and other similar markers can identify overweight youth with decreased in vivo insulin sensitivity and inflammation.

\section{Conclusion}

The TG: HDL-C ratio can be utilized not only as a reliable independent marker for insulin resistance and inflammation, but also for identification of atherosclerosis risk in obese children and adolescents. Furthermore, defining insulin resistance is difficult since no clear guidelines or cutoffs exist for either HOMA-IR or fasting insulin concentrations. In addition, the use of glucose clamps method for diagnosis of insulin resistance, which is invasive, time consuming, and not practical in a clinical setting. Thus, surrogates of insulin resistance, which would be more practical and reliable in clinical settings, should be proposed. Our study demonstrates that the pro-inflammatory state likely tracks from childhood. The TG: HDL-C ratio could prove to be a useful, readily available biomarker of CMR in obese youth that could provide opportunities for prevention of atherosclerosis in adulthood.

\section{Acknowledgment}

This study was funded by the Diabetes Research Fund, Department of Pediatrics, Medical College of Wisconsin, Milwaukee, WI, USA.

\section{Authors' Contributions}

Ola Kawadry contributed to data collection and writing the manuscript. Jessica Kichler contributed to data analysis and writing the manuscript. Raymond G. Hoffmann contributed to data analysis and editing. Mahua Dasgupta contributed to data analysis. Ramin Alemzadeh contributed to data collection, data analysis, and writing and editing the manuscript.

\section{References}

1. Berenson GS, Srinivasan SR, Bao W, Newman WP 3rd, Tracy RE, et al. (1998) Association between multiple cardiovascular risk factors and atherosclerosis in children and young adults. The Bogalusa Heart Study. N Engl J Med 338: 1650-6.

2. van den Berg E, Biessels GJ, Stehouwer CDA, Kappelle LJ, Heine RJ, et al. (2010) Ten-year time course of risk factors for increased carotid intima-media thickness: the Hoorn Study. Eur J Cardiovasc Prev Rehabil 17: 168-74.

3. Vega GL, Barlow CE, Grundy SM, Leonard D, DeFina LF (2014) Triglyceride-to-high- density-lipoprotein-cholesterol ratio is an index of heart disease mortality and of incidence of type 2 diabetes mellitus in men. J Investig Med 62: 345-9.

4. Morrison JA, Friedman LA, Gray-McGuire C (2007) Metabolic syndrome in childhood predicts adult cardiovascular disease 25 years later: the Princeton Lipid Research Clinics Follow-up Study. Pediatrics 120: 340-5.

5. McCall A, Raj R (2009) Exercise for prevention of obesity and diabetes in children and adolescents. Clin Sports Med 28: 393-421.

6. McLaughlin T, Reaven G, Abbasi F, Lamendola C, Saad M, et al. (2005) Is there a simple way to identify insulin resistant individuals at increased risk of cardiovascular disease? Am J Cardiol 96: 399-404.

7. Liang J, Fu J, Jiang Y, Dong G, Wang X, et al. (2015) Triglycerides and high-density lipoprotein cholesterol ratio compared with homeostasis model assessment insulin resistance indexes in screening for metabolic syndrome in the Chinese obese children: a cross section study. BMC Pediatr 15: 138-44.

8. Karelis AD, Pasternyk SM, Messier L, St-Pierre DH, Lavoie JM, et al. (2007) Relationship between insulin sensitivity and the triglyceride-HDL-C ratio in overweight and obese postmenopausal women: a MONET study. Appl Physiol Nutr Metab 32: 1089-96.

9. Caprio S (1999) Relationship between abdominal visceral fat and metabolic risk factors in obese adolescents. Am J Human Biol 11: $259-66$.

10. Roh EJ, Lim JW, Ko KO, Cheon EJ (2007) A useful predictor of early atherosclerosis in obese children: serum high-sensitivity c-reactive protein. J Korean Med Sci 22: 192-7.

11. Koenig W, Sund M, Fröhlich M, Fischer HG, Löwel H, et al. (1999) C-Reactive protein, a sensitive marker of inflammation, predicts future risk of coronary heart disease in initially healthy middle-aged men: results from the MONICA (Monitoring Trends and Determinants in Cardiovascular Disease) Augsburg Cohort Study, 1984 to 1992. Circulation 99: 237-42.

12. Lee WY, Park JS, Noh SY, Rhee EJ, Sung KC, et al. (2004) C-reactive protein concentrations are related to insulin resistance and metabolic syndrome as defined by the ATP III report. Int J Cardiol 97: 101-6.

13. Fredrikson GN, Hedblad B, Nilsson JA, Alm R, Berglund G, et al. (2004) Association between diet, lifestyle, metabolic cardiovascular risk factors, and plasma C-reactive protein levels. Metabolism 53: 1436-42.

14. Soriano-Guillén L1, Hernández-García B, Pita J, Domínguez-Garrido N, Del Río-Camacho G, et al. (2008) High-sensitivity c-reactive protein is a good marker of cardiovascular risk in obese children and adolescents. Eur J Endocrinol. 159: R1-4.

15. de Ferranti SD, Gauvreau K, Ludwig DS, Neufeld EJ, Newburger JW, et al. (2004) Prevalence of the metabolic syndrome in American adolescents: findings from the Third National Health and Nutrition Examination Survey. Circulation 110: 2494-7.

16. Hannon TS, Bacha F, Lee SJ, Janosky J, Arslanian SA (2006) Use of markers of dyslipidemia to identify overweight youth with insulin resistance. Pediatr Diabetes 7: 260-6.

17. Cole TJ, Bellizzi MC, Flegal KM, Dietz WH (2000) Establishing a standard definition for child overweight and obesity worldwide: international survey. BMJ 320: $1240-3$

18. Kettaneh A, Heude B, Lommez A, Borys JM, Ducimetière P, et al. (2005) Reliability of bioimpedance analysis compared with other adiposity measurements in children: the FLVS II study. Diabetes Metab 31: 534-41.

19. Matthews DR, Hosker JP, Rudenski AS, Naylor BA, Treacher DF, et al. (1985) Homeostasis model assessment; insulin resistance and beta cell function from fasting plasma glucose and insulin concentrations in man. Diabetologia 28: 412-9. 
20. Friedewald WT, Levy RI, Fredrickson DS (1972) Estimation of the concentration of low density lipoprotein cholesterol without use of preparative ultracentrifuge. Clin Chem 18: 499-502.

21. Ford ES, Li C, Zhao G, Pearson WS, Mokdad AH (2008) Prevalence of the metabolic syndrome among U.S. adolescents using the definition from the International Diabetes Federation. Diabetes Care 31: 587-9.

22. Weiss R, Dziura J, Burgert TS, Tamborlane WV, Taksali SE, et al. (2004) Obesity in the metabolic syndrome in children and adolescents. N Eng J Med 350: 2362-74.

23. Dhuper S, Sakowitz S, Daniels J, Buddhe S, Cohen HW (2009) Association of lipid abnormalities with measures and severity of adiposity and insulin resistance among overweight children and adolescents. J Clin Hypertens 11: 594-600.

24. Quijada Z, Paoli M, Zerpa Y, Camacho N, Cichetti R, et al. (2008) The triglyceride/HDL-cholesterol ratio as a marker of cardiovascular risk in obese children; association with traditional and emergent risk factors. Pediatric Diabetes 9: 464-71.

25. Sumner AE, Finley KB, Genovese DJ, Criqui MH, Boston RC (2005) Fasting Triglyceride-HDL cholesterol ratio are not markers of insulin resistance in African Americans. Arch Intern Med 165: 1395-400.

26. Després JP, Couillard C, Gagnon J, Bergeron J, Leon AS, et al. (2000) Race, visceral adipose tissue, plasma lipids, and lipoprotein lipase activity in men and women: the Health, Risk Factors, Exercise Training, and Genetics (HERITAGE) Family Study. Arterioscler Thromb Vasc Biol 20: 1932-8.

27. Sumner AE, Vega GL, Genovese DJ, Finley KB, Bergman RN, et al. (2005) Normal triglyceride levels despite insulin resistance in African-Americans: role of lipoprotein lipase. Metabolism 54: 902-9.

28. Hallman DM, Srinivasan SR, Elkasabany A, Boerwinkle E, Berenson GS (2001) The Ser447-Stop polymorphism of lipoprotein lipase is associated with variation in longitudinal serum high- density lipoprotein-cholesterol profiles: The Bogalusa Heart Study. Metabolism 50: 894-904.

29. Ridker PM (2001) High-sensitivity C-reactive protein: potential adjunct for global risk assessment in the primary prevention of cardiovascular disease. Circulation 103: 1813-8.

30. Rutter MK, Meigs JB, Sullivan LM, D’Agostino RB Sr, Wilson PW (2004) C-reactive protein, the metabolic syndrome, and prediction of cardiovascular events in the Framingham Offspring Study. Circulation 110: 380-5.

31. Kivimaki M, Lawlor DA, Juonala M, Smith GD, Elovainio M, et al. (2005) Lifecourse socioeconomic position, C-reactive protein, and carotid intima-media thickness in young adults: the cardiovascular risk in Young Finns Study. Arterioscler Thromb Vasc Biol 25: 2197-202.

32. Trujillo ME, Scherer PE (2006) Adipose tissue-derived factors: impact on health disease. Endocr Rev 27: 762-78.

33. Musso C, Graffigna M, Soutelo J, Honfi M, Ledesma L, et al. (2011) Cardiometabolic risk factors as apolipoprotein B, triglyceride/HDL- cholesterol ratio and c-reactive protein, in adolescents with and without obesity: cross- sectional study in middleclass suburban children. Pediatr Diabetes 12: 229-34.

34. Ridker PM (2003) Clinical application of C-reactive protein for cardiovascular disease detection and prevention. Circulation 107: 363-9.

35. Guran O, Akalin F, Ayabakan C, Dereli FY, Haklar G (2007) High-sensitivity C-reactive protein in children at risk for coronary artery disease. Acta Paediatr 96: 1214-9.

36. Di Bonito P, Moio N, Scilla C, Cavuto L, Sibilio G, et al. (2012) Usefulness of the high triglyceride-to-HDL cholesterol ratio to identify cardiometabolic risk factors and preclinical signs of organ damage in outpatient children. Diabetes Care 35: 158-62.

37. Ford ES, Giles WH, Myers GL, Rifai N, Ridker PM, et al. (2003) C-reactive Protein Concentration Distribution among US Children and Young Adults: Findings from the National Health and Nutrition Examination Survey, 1999-2000. Clin Chem 49: 1353-7.

38. Syme C, Abrahamowicz M, Leonard GT, Perron M, Pitiot A, et al. (2008) Intra-abdominal adiposity and individual components of the metabolic syndrome in adolescence: sex differences and underlying mechanisms. Arch Pediatr Adolesc Med 162: 453-61.

39. Khera A, Vega GL, Das SR, Ayers C, McGuire DK, et al. (2009) Sex differences in the relationship between C-reactive protein and body fat. J Clin Endocrinol Metab 94: 3251-8.

40. Eldeirawi K, Lipton RB (2003) Predictors of hemoglobin A1c in a national sample of nondiabetic children: the Third National Health and Nutrition Examination Survey, 1988-1994. Am J Epidemiol 157: 624-32.

41. Ziemer DC, Kolm P, Weintraub WS, Vaccarino V, Rhee MK, et al. (2010) Glucose-independent, black-white differences in hemoglobin A1c levels: A crosssectional analysis of 2 studies. Ann Intern Med 152: 770-7.

42. Arslanian SA, Lewy VD, Danadian K (2001) Glucose intolerance in obese adolescents with polycystic ovary syndrome: roles of insulin resistance and beta-cell dysfunction and risk of cardiovascular disease. J Clin Endocrinol Metab 86: 66-71.

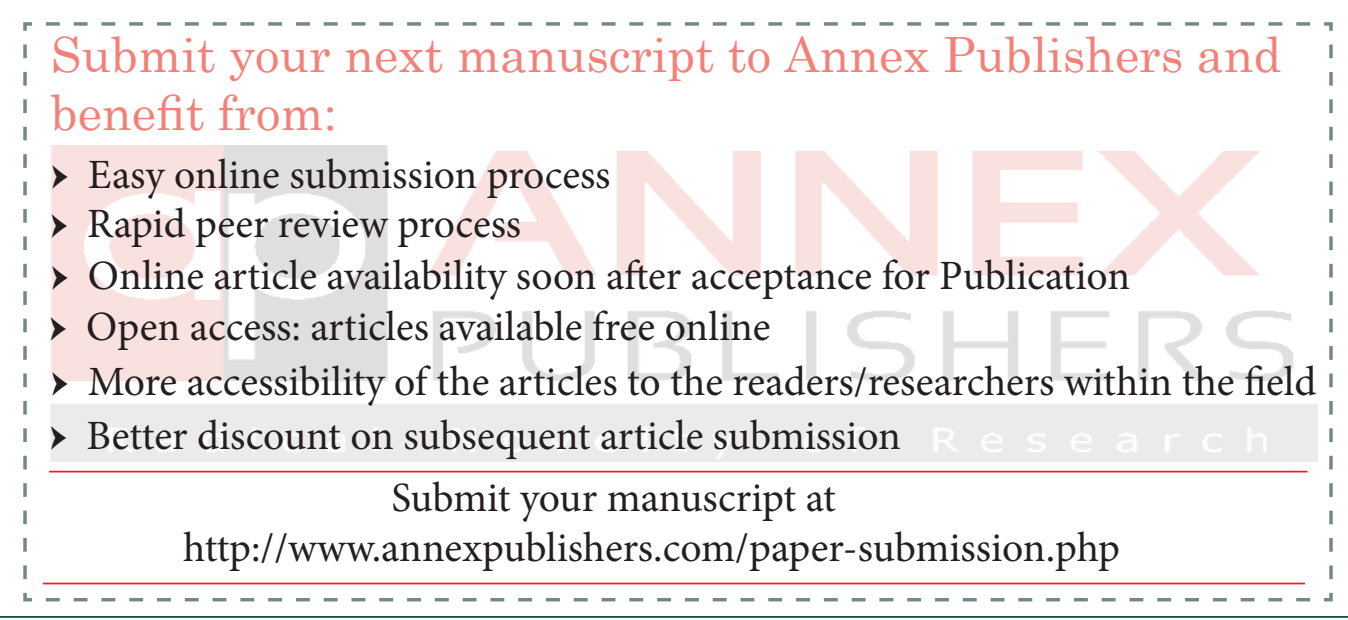

